\section{Comparison of Two Intubation Techniques during General Anesthesia. Laryngeal Mask for Intubation (Fastrach) vs Endotracheal Intubation}

\section{Leopoldo Wulff1*, Sergio González', Marco Aurelio Puente', Antonio Castellanos ${ }^{2}$, Tomás Déctor ${ }^{3}$ and Alfonso Quiroz ${ }^{4}$}

${ }^{1}$ Hospital of Specialties, "Dr. Bernardo Sepúlveda G", Centro Médico Nacional Siglo XXI, Instituto Mexicano del Seguro Social, Universidad Nacional Autónoma de México, Mexico

${ }^{2}$ Deputy Head of the Division of Education and Medical Research, Specialty Hospital, "Dr. Bernardo Sepúlveda G", Centro Médico Nacional Siglo XXI, Instituto Mexicano del Seguro Social, Universidad Nacional Autónoma de México, Mexico

${ }^{3} \mathrm{Holder}$ of the University Course of Specialization in Anesthesiology, Specialty Hospital, "Dr. Bernardo Sepúlveda G", Centro Médico Nacional Siglo XXI, Instituto Mexicano del Seguro Social, Universidad Nacional Autónoma de México, Mexico

${ }^{4}$ Holder of the University Course of Specialization in Anesthesiology (E), Specialty Hospital, "Dr. Bernardo Sepúlveda G", Centro Médico Nacional Siglo XXI, Instituto Mexicano del Seguro Social, Universidad Nacional Autónoma de México, Mexico

\begin{abstract}
Introduction: The American Society of Anesthesiology (ASA) has developed in recent years an algorithm to follow in case of presenting a difficult or unexpected airway. In said algorithm various techniques or mechanisms different from direct laryngoscopy are men-
\end{abstract}

*Corresponding author: Leopoldo Wulff, Hospital of Specialties, "Dr. Bernardo Sepúlveda G", Centro Médico Nacional Siglo XXI, Instituto Mexicano del Seguro Social, Universidad Nacional Autónoma de México, Mexico, Tel: +58 4143264549; E-mail: leowulff@yahoo.com

Citation: Wulff L, González S, Puente MA, Castellanos A, Déctor T, et al (2018) Comparison of Two Intubation Techniques during General Anesthesia Laryngeal Mask for Intubation (Fastrach) vs Endotracheal Intubation. J Anesth Clin Care 5: 31

Received: September 20, 2018; Accepted: December 5, 2018; Published: December 19, 2018

Copyright: (c) 2018 Wulff L, et al. This is an open-access article distributed under the terms of the Creative Commons Attribution License, which permits unrestricted use, distribution, and reproduction in any medium, provided the original author and source are credited. tioned that can help in a pressing situation. The laryngeal mask for intubation (Fastrach) is a device that has increased its popularity by playing an important role in the management of the airway

Objective: To demonstrate that the laryngeal mask for intubation (Fastrach) is a useful device for the management of the airway and that it causes fewer complications than traditional intubation in patients undergoing general anesthesia.

Materials and methods: We studied 100 patients of both sexes and ages between 20 and 90 years, physical status ASA I, II and III, scheduled for elective surgery and general anesthetic technique. The time of Fastrach intubation and endotracheal intubation in seconds, hemodynamic and oxygen saturation values and finally the complications during and at the end of the procedure (oral bleeding, mucosal laceration, and impossibility of intubation, odynophagia and dysphonia) were measured.

Results: A statistically significant intubation time was obtained with $p<0.05$ for the EIT with a time of $25.38 \mathrm{sec} \pm 13.68 \mathrm{sec}$ and for the $\mathrm{ML}$ (Fastrach) of $57.04 \mathrm{sec} \pm 32.68 \mathrm{sec}$, the hemodynamic behavior remained practically the same in both cases. Groups and complications presented were more notable in the EIT mainly odynophagia and dysphonia.

Conclusion: The use of the laryngeal mask for Fastrach intubation as an alternative in direct laryngoscopy for endotracheal intubation in patients with easy airway is viable, demonstrating fewer complications than traditional intubation, as well as being safe, useful and effective.

Keywords: Endotracheal intubation; Fastrach; Laryngeal mask

\section{Background}

The anesthesiologist, in his daily practice, is faced daily with the management of the airway; this is in the possibility of providing minimal essential care to any patient who will undergo a surgical anesthetic procedure. The possibility of intubation will be latent in all cases, the maneuvers and procedures aimed at maintaining a permeable route with adequate ventilation are not exempt from risk. $4.6 \%$ of endotracheal intubations are associated with complications, among which the most common may be ventilation and difficult intubation [1]. For endotracheal intubation to be successful, a meticulous clinical and anatomophysiological assessment is required, in such a way that manipulation of the airway is simple and safe. However, it is often difficult and represents a challenge for anesthesiologists, even the most experienced [2]. The American Society of Anesthesiology (ASA) has developed in recent years an algorithm to follow in case of presenting a difficult and unexpected airway. It has submitted modifications according to the experience and needs of the case. In said algorithm, it is mentioned in different techniques or mechanisms different from direct laryngoscopy that can solve a pressing situation at a certain moment [3].

Infraglottic application techniques have been developed for the management of the airway, within which we can recognize Jet ventilation, cricothyroidectomy and tracheostomy. Others are of supraglottic application, such as ventilation with face mask, Guedel COPA 
cannula and Laryngeal Mask (ML), finally there are transglottic application techniques different to endotracheal intubation through direct laryngoscopy and blind digital intubation, nasotracheal intubation blindly or guided with direct laryngoscopy, the use of luminous stylet, fibro-laryngoscopy, retrograde intubation and guided intubation through ML [4]. The development of ML initiated in 1981 by Dr. Archie Brain, British anesthesiologist of the Royal London Hospital. Dr. Brain suggested that Goldman's dental mask could be modified to fit around the larynx and not in the nose. His intention was the specific search for an airway that was more practical than the facial mask and less invasive than the endotracheal cannula $[5,6]$.

\section{Some modifications related to ML are the following:}

A rigid tube of stainless steel shorter in size, which allows better guidance of the mask when the Endotracheal Cannula (CET) passes through it, with a good ratio of the internal and external diameter (13/15 mm), covered of silicone and which can be desterilized. An integral $15 \mathrm{~mm}$ connector that allows it to be used as the conventional ML avoids accidental disconnections and allows the passage of a CET of $8.0 \mathrm{~mm}$ with inflatable sleeve. A curvature that follows the anatomy of the CET with which we can avoid the manipulation of the neck, the head and the insertion of the fingers, since the pressure against the palate can be applied externally; also promotes the alignment of the CET towards the glottis vestibule facilitating the insertion of the same through this structure, diminishing the possibility of trauma.

Integrated handle of the ML of intubation which allows a greater and easier handling while holding firm the device during the insertion of the CET. V-shaped ramp which fixes the TSC toward the center and guides it in the direction reducing the risk of trauma to the arytenoids cartilages or the displacement of the tube into the esophagus. Bar of elevation of the epiglottis: a membrane placed in the distal opening of the ML of intubation that keeps the epiglottis out of any possibility of being able to obstruct said opening while protecting and elevating it during the insertion process of the probe [7,8]. Because of the characteristics of our hospital in being always at the forefront of medicine, we decided to carry out this work to obtain an experience in the management of the airway comparing two intubation techniques for general anesthesia.

\section{Objective}

To demonstrate that the laryngeal mask for Fastrach intubation is a useful device for the management of the airway and which causes fewer complications than traditional intubation in patients undergoing general anesthesia.

\section{Materials and Methods}

\section{Research design}

He studied quasi-experimental, prospective, and longitudinal and comparative. It is a clinical, longitudinal, comparative study, where you will study that the laryngeal mask for intubation (Fastrach) is a useful device for the management of the airway and that it causes fewer complications than traditional intubation in patients undergoing general anesthesia.

\section{Working universe}

Patients undergoing elective surgery at the Hospital de Especialidades CMN Siglo XXI, in the period from February 2000 to February 2001.

\section{Description of the variables}

Dependent variables: Utility and safety of Fastrach according to: hemodynamic values, oxygen saturation, time of Fastrach placement as well as endotracheal cannula, transoperative complications, postoperative complications.

Independent variables: Laryngeal mask for intubation (Fastrach) and Endotracheal Cannula (ETC). They are qualitative variables, with a dichotomous qualitative measurement scale. Demographics (sex, age, weight and height), Predictive (physical status according to ASA, valuation of the airway according to the assessment of Mallampati, Pati and others), operative, respiratory and hemodynamic.

\section{Sample selection}

Convenience sampling was used and a sample size of 100 patients was estimated.

\section{Selection criteria}

Criterion of inclusion: Patients who agreed to participate in the study, patients of either sex scheduled for elective surgery, patients scheduled for general anesthesia, patients physical condition ASA I, II and III, ages between 20 and 90 years old.

Non-inclusion criteria: Patients who presented a predictive index for inadequate mouth opening, patients with pathology of the respiratory system, patients with risk of regurgitation or bronchoaspiration (previous surgeries of the upper gastrointestinal tract, hiatal hernia, gastro-esophageal reflux, ulceropéptica disease and those patients who have not fulfilled the fast properly), patients with oral or pharyngeal tumors, patients with a surgical historya of tracheostomy and/or laryngeal surgery, patients who had a history or risk of infection by hepatitis virus, cytomegalovirus or HIV.

Exclusion criteria: Patients who refused to participate in the study, impossibility of placement of the laryngeal mask for Fastrach intubation or intubation of the endotracheal cannula.

\section{Procedure}

Once the patient was in the operating room, he was monitored with a cardio-scope, non-invasive blood pressure (systolic, diastolic and mean), heart rate and pulse oximeter, taking these as $\mathrm{T} 1$ values. When the Fastrach was placed, the face opposite the distal opening was lubricated with water-soluble gel, Fastrach \# 3 was used. The sterile conventional Endotracheal Cannula (ETC) was also lubricated to allow frictionless sliding. Internal diameter cannulas \# 7.0, 7.5 and $8.0 \mathrm{~mm}$ were used.

Prior oxygenation with a face mask with $100 \%$ oxygen 3 liters/ min, the induction of anesthesia was started (the use of medications and their respective doses were left to the anesthesiologist protocol). Three average minutes were waited for the peak action of the administered drugs and the hemodynamic values and oxygen saturation were taken again as a second time T2. After placement of the Fastrach and/ or endotracheal cannula and once the airway was secured, the cuff was insufflated respectively; the hemodynamic and oxygen saturation values represented as $\mathrm{T} 3$ were measured again. The placement of 
LMA-Fastrach and/or endotracheal intubation was performed by the anesthesia resident. The permeability of the airway was verified with thoracic expansibility and auscultation of respiratory sounds, which resulted in successful intubation. The total time of placement of the Fastrach and the endotracheal cannula was measured (independently if it was achieved in a first, second or third attempt). The intubation time was ruled out if it was failed and if direct laryngoscopy had to be performed. It was taken as total time, as it elapses since the anesthesiologist takes either the Fastrach or the laryngoscope until successful intubation is performed.

Likewise, it was analyzed whether there was any complication during the procedure or after the procedure, such as oral bleeding, laceration of the mucosa, and assessment of the first and 24 hours afterwards if the patient presented odynophagia (sore throat) and/or dysphonia (hoarseness). Using the analog visual scale (EVA), where zero indicates absence of pain or hoarseness and 10 the worst pain or hoarseness that the patient could imagine. Dysphonia/odynophagia when presented was indicating in the postoperative mediate pharmacaine $10 \%$ solution topical spray used.

\section{Statistical analysis}

Three different types of analysis will be used. The first is the descriptive analysis in which position measurements are calculated. The second is the graphic analysis, which is based on bar graphs, sector diagrams, frequency histograms; the third analysis is the statistical significance or validation, it is based on the comparison of proportions based on the sampling distribution for discrete variables through the chi-square test, for continuous variables we will use comparison by difference of means with unequal variances based on the t-student distribution. All the contrasts of hypotheses will be carried out with $\alpha$ $=0.05$, that is, $95 \%$ confidence.

\section{Results}

The sample size 100 patients, divided into two groups of 50 patients. Group 1 for Fastrach and group 2 for traditional intubation. 59 of the female sex (59\%), 36 women from group 1 and 23 from group 2, and 41 from male sex (41\%). 14 of group 1 against 27 of group 2, ages between 20 and 90 years, average of $50.78 \pm 16.93$ years for the first group and $56.06 \pm 7.00$ years for the second group, the weight in average kilograms was $65.84 \mathrm{kgs}$ against $68.04 \mathrm{kgs}$ with a standard deviation of 9.45 and 13.5 , the average height was 1.57 meters \pm 0.067 in group 1 meanwhile in group 2 with an average height of 1.59 meters \pm 0.054 . The time for intubation in seconds was significant with $\mathrm{p}<0.05$ for the second group of $25.38 \pm 13.68 \mathrm{sec}$ while group 1 was $57.04 \pm 32.68 \mathrm{sec}$ (Table 1). The physical condition ASA I in 25 patients, ASA II in 61 patients and ASA III in 14 patients, the referals services were: 65 ophthalmology patients, 10 gastro-surgery patients, 23 otorhinolaryngology patients, 1 head and neck patient and 1 angiology patient. The predictive index for airway assessment was measured according to the Mallampati classification; Mallampati I in 23 patients, II in 63 patients and III in 14 patients (Table 2). According to Patil's classification, it is expressed in percentages according to the group; group 1, $80 \%$ grade I and $20 \%$ grade II, while group 2, $88 \%$ grade I and $12 \%$ grade II (Table 3 ).

\begin{tabular}{|c|c|c|c|}
\cline { 2 - 4 } \multicolumn{1}{c|}{} & Fastrach & IET Tradicional & $\mathbf{p}$ \\
\hline Patients & 50 & 50 & NS \\
\hline Gender Male/Female) & $14 / 36$ & $27 / 23$ & NS \\
\hline Age (years) & $50.78 \pm 16.93$ & $56.06 \pm 7.00$ & NS \\
\hline Heigh (Meters) & $1.57 \pm 0.067$ & $1.59 \pm 0.054$ & NS \\
\hline Weight (Kilograms) & $65.84 \pm 9.45$ & $68.04 \pm 13.50$ & NS \\
\hline (Intubation time (seconds & $32.68 \pm 57.04$ & $13.68 \pm 25.38$ & $0.05>$ \\
\hline
\end{tabular}

Table 1: General characteristics.

$\mathrm{NS}=$ No significative; $\mathrm{P}=$ Probability $; \mathrm{EIT}=$ Endotracheal Intubation

\begin{tabular}{|c|c|c|c|c|}
\cline { 3 - 5 } \multicolumn{2}{|c|}{} & $\begin{array}{c}\text { Group1 } \\
\text { (Fastrach) }\end{array}$ & $\begin{array}{c}\text { Group 2 } \\
\text { (Traditional ETI) }\end{array}$ & Total \\
\hline \multirow{3}{*n}{ ASA } & I & 18 & 7 & 25 \\
& II & 29 & 32 & 61 \\
& III & 3 & 11 & 14 \\
\hline \multirow{4}{*}{ Service } & OPHT & 28 & 37 & 65 \\
Referal & GCX & 2 & 8 & 10 \\
& ORL & 19 & 4 & 23 \\
& H\&N Cx & 0 & 1 & 1 \\
& ANG & 0 & 1 & 1 \\
\hline \multirow{2}{*}{ Mallampati } & I & 19 & 4 & 23 \\
Clasification & II & 25 & 38 & 63 \\
& III & 4 & 10 & 14 \\
\hline
\end{tabular}

Table 2: Qualitative variables.

\begin{tabular}{|c|c|c|}
\cline { 2 - 3 } \multicolumn{1}{c|}{} & Grade I & Grade II \\
\hline Traditional ETI & $12 \%$ & $88 \%$ \\
\hline Fastrach $\mathrm{p}>0,05$ & $20 \%$ & $80 \%$ \\
\hline
\end{tabular}

Table 3: Patil classification.

The hemodynamic behavior was evaluated based on three parameters (MAP, FC, Sat $\mathrm{O}_{2} \%$ ), with measurements in the three aforementioned times (T1, T2 and T3) analyzing the average. The MAP premedication for the Fastrach was $106 \mathrm{~mm} \mathrm{Hg}$ in group 1 and $100 \mathrm{~mm}$ $\mathrm{Hg}$ for group 2. The post-medication MAP for group 1 was $88 \mathrm{~mm}$ $\mathrm{Hg}$ while group 2 was $81 \mathrm{~mm} \mathrm{Hg}$ and the post-intubation MAP was $87 \mathrm{~mm} \mathrm{Hg}$ group 1 and $84 \mathrm{~mm} \mathrm{Hg}$ for group 2 (Table 4).

\begin{tabular}{|c|c|c|}
\hline & $\begin{array}{c}\text { Group 1 } \\
\text { (Fastrach) } \\
\text { mm HG }\end{array}$ & $\begin{array}{c}\text { Group } 2 \\
\text { (Traditional ETI) } \\
\text { mm HG }\end{array}$ \\
\hline Pre-medication MAP & 106 & 100 \\
\hline Post-medication MAP & 88 & 81 \\
\hline Post Intubation MAP & 87 & 84 \\
\hline
\end{tabular}

Table 4: Mean arterial pressure events.

Complications during the procedure were assessed according to: mild bleeding in a patient of group 1 and absent in 99 patients; no mucosal lacerations were evidenced in both groups. The impossibility of intubation in the first group (Fastrach) occurred in 3 patients but they were successful in the second group (Traditional ETI) at 100\%. The intensity of the odynophagia assessed by EVA (1-3 pts) during the 
first and 24 hours after the event was presented in 42 and 12 patients in group 1 (Fastrach), 8 and 2 patients in group 2 (Traditional ETI). The intensity of the dysphonia assessed by EVA (1-2 pts) during the first and 24 hours after the event was presented in 18 and 2 patients in group 1 (Fastrach), 8 and 3 patients in group 2 (Traditional ETI) (Table 5).

\begin{tabular}{|c|c|c|c|c|}
\cline { 2 - 5 } \multicolumn{1}{c|}{} & $\begin{array}{c}\mathbf{1}^{\circ} \text { Hour } \\
\text { fastrach }\end{array}$ & $\begin{array}{c}\mathbf{2 4} \text { Hours } \\
\text { fastrach }\end{array}$ & $\mathbf{1}^{\circ}$ Hour fastrach & $\begin{array}{c}\mathbf{2 4} \text { Hours } \\
\text { fastrach }\end{array}$ \\
\hline $\begin{array}{c}\text { Odynophagia } \\
\text { EVA (1-3 pts) }\end{array}$ & 42 & 12 & 8 & 2 \\
\hline $\begin{array}{c}\text { Dysphonia } \\
\text { EVA (1-2 pts) }\end{array}$ & 18 & 2 & 8 & 3 \\
\hline
\end{tabular}

Table 5: Odynophagia-Dysphonia.

\section{Ethical Considerations}

The control of the airway results for the anesthesiologist in the possibility of providing minimal essential care to any patient who will undergo a surgical anesthetic procedure. In order for intubation to be successful, a meticulous clinical evaluation is required, in such a way that manipulation of the airway is simple and safe to achieve an adequate gas exchange. Among the different techniques described for the management of the airway, the use of ML for Fastrach is a useful, safe and effective alternative.

\section{Discussion}

The results of this feasibility study have shown that, in patients of both sexes with predictive index of non-difficult airway, the laryngeal mask for Fastrach intubation can be successfully used for oxygenation and ventilation, demonstrating that the hemodynamic behavior in both groups shown by the patients in all three times during intubation did not show statistically significant differences. Kihara, et al., [9] published similar results in their study tracheal intubation with the Macintosh laryngoscope versus intubating LMA in adults with normal airways.

Regarding the intubation time, it was observed that the intubation through the Fastrach takes a time of $57.04 \pm 32.68 \mathrm{sec}$ compared with traditional intubation with a time of $25.38 \pm 13.86 \mathrm{sec}$. It is important to note that the more experience you have in daily practice with the Fastrach can reduce these times by making the anesthesiologist more skilled in his daily work, also commenting that the traditional intubation, its intubation time, will depend on the type of laryngoscope blade what is used as well as the experience of the person who makes it.

Regarding intubation success, the attempt in our study was $100 \%$, while the Wulff-Puente study achieved 58\% at the first attempt, $32 \%$ at the second attempt and $4 \%$ at the third attempt, compared to the international literature. Joo and Rose show a $97 \%$ success rate, where $90 \%$ went to the first attempt, $6.7 \%$ to the second attempt and $3.3 \%$ to the third attempt [10].

It was also shown that the complications of the first group manifested by odynophagia and dysphonia assessed by the Visual Analogue Scale (VAS) showed a lower index in which they show the results obtained by Wulff-Puente [11], understanding that it is a subjective assessment of pain compared in different ethnic groups and races.
There are authors who have defended the use of the laryngeal mask for intubation Fastrach in patients with difficult airway. In the literature consulted there are a limited number of satisfactory intubations with Fastrach in patients with difficult airway as reported by Joo HS and Rose DK [12] who describe intubation LMA with and without fiberoptic guidance. Nakazawa K, et al., [13] with the use of LMA-Fastrach in blind endotracheal intubation in patients undergoing cervical spine operation present a good experience. In conclusion we consider that we cannot oppose the use of Fastrach for the use of endotracheal intubations in patients with difficult airway until it becomes available of more evidence on its efficacy and in addition to continuing studies aimed at comparing the usefulness and efficacy of intubations with instruments of frequent use in the management of the airway.

\section{Conclusions}

The use of the laryngeal mask for Fastrach intubation as an alternative in direct laryngoscopy for endotracheal intubation in patients with easy air is feasible and has shown to have fewer complications during its use as well as being useful, safe and effective.

The hemodynamic behavior shown in both groups and the discomfort or complications after the procedure showed no statistical differences.

We suggest becoming familiar with the use of new work instruments for the management and control of the airway before attempting to use it with difficult airway patients.

\section{References}

1. Asai T, Koga K, Vaughan RS (1998) Respiratory complications associated with tracheal intubation and extubation. Br J Anaesth 80: 767-775.

2. Abran KJ, Grande CM (1994) Airway management of the trauma, patient with cervical spine injury. Curp op Anaesth 7: 184-190.

3. Benumof JL. The ASA difficult airway algorithm: New thoughts and considerations. ASA. Annual Refresher Couse Lectures, October 17-21, 1998 236. Copyright 1998 by the American Society of Anesthesiologists, Inc. Printed in the United States of America.

4. Heath ML, Allagain J (1991) Intubation through the laryngeal mask. A technique for unexpected difficult intubation. Anaesthesia 46: 545-558.

5. Rhee KJ, Green W, Holcroft JW, Mangili JAA (1990) Oral intubation in the multiply injured patient: The risk of exacerbating spinal cord damage. Annals of Emergency Medicine 19: 511-514.

6. Brain AI (1991) The development of the Laryngeal Mask--a brief history of the invention, early clinical studies and experimental work from which the Laryngeal Mask evolved. Eur J Anaesthesiol Suppl 4: 5-17.

7. Langenstein H, Moller F (1998) Early results with laryngeal mask intubation. Anaesthesist 47: 311-319.

8. Brain AI, Verghese C, Addy EV, Kapila A (1997) The intubating laryngeal mask. I: Development of a device for intubation of the trachea. Br J Anaesth 79: 699-703.

9. Kihara S, Watanabe S, Taguchi N, Suga A, Brimacombe JR (2000) Tracheal intubation with the Macintosh laryngoscope versus intubating laryngeal mask airway in adults with normal airways. Anaesth Intensive Care 28: 281-286. 
Citation: Wulff L, González S, Puente MA, Castellanos A, Déctor T, et al. (2018) Comparison of Two Intubation Techniques during General Anesthesia. Laryngeal Mask for Intubation (Fastrach) vs Endotracheal Intubation. J Anesth Clin Care 5: 31.

10. Joo H, Rose K (1998) Fastrach--a new intubating laryngeal mask airway: successful use in patients with difficult airways. Can J Anaesth 45: 253256

11. Wulff L, Puente M, Castellanos A, Déctor T (2001) Uso de la máscara laringea para intubación (fastrach), experiencia inicial en el HE CMN SXXI; Jornada médicos residentes HE CMN SXXI 25 y 26 Enero.
12. Joo HS, Rose DK (1999) The intubating laryngeal mask airway with and without fiberoptic guidance. Anesth Analg 88: 662-666.

13. Nakazawa K, Tanaka N, Ishikawa S, Ohmi S, Ueki M, et al. (1999) Using the intubating laryngeal mask airway (LMA-Fastrach) for blind endotracheal intubation in patients undergoing cervical spine operation. Anesth Analg 89: 1319-1321. 


\section{di}

Journal of Anesthesia \& Clinical Care

Journal of Addiction \& Addictive Disorders

Advances in Microbiology Research

Advances in Industrial Biotechnology

Journal of Agronomy \& Agricultural Science

Journal of AIDS Clinical Research \& STDs

Journal of Alcoholism, Drug Abuse \& Substance Dependence

Journal of Allergy Disorders \& Therapy

Journal of Alternative, Complementary \& Integrative Medicine

Journal of Alzheimer's \& Neurodegenerative Diseases

Journal of Angiology \& Vascular Surgery

Journal of Animal Research \& Veterinary Science

Archives of Zoological Studies

Archives of Urology

Journal of Atmospheric \& Earth-Sciences

Journal of Aquaculture \& Fisheries

Journal of Biotech Research \& Biochemistry

Journal of Brain \& Neuroscience Research

Journal of Cancer Biology \& Treatment

Journal of Cardiology: Study \& Research

Journal of Cell Biology \& Cell Metabolism

Journal of Clinical Dermatology \& Therapy

Journal of Clinical Immunology \& Immunotherapy

Journal of Clinical Studies \& Medical Case Reports

Journal of Community Medicine \& Public Health Care

Current Trends: Medical \& Biological Engineering

Journal of Cytology \& Tissue Biology

Journal of Dentistry: Oral Health \& Cosmesis

Journal of Diabetes \& Metabolic Disorders

Journal of Dairy Research \& Technology

Journal of Emergency Medicine Trauma \& Surgical Care

Journal of Environmental Science: Current Research

Journal of Food Science \& Nutrition

Journal of Forensic, Legal \& Investigative Sciences

Journal of Gastroenterology \& Hepatology Research

Journal of Gerontology \& Geriatric Medicine
Journal of Genetics \& Genomic Sciences

Journal of Hematology, Blood Transfusion \& Disorders

Journal of Human Endocrinology

Journal of Hospice \& Palliative Medical Care

Journal of Internal Medicine \& Primary Healthcare

Journal of Infectious \& Non Infectious Diseases

Journal of Light \& Laser: Current Trends

Journal of Modern Chemical Sciences

Journal of Medicine: Study \& Research

Journal of Nanotechnology: Nanomedicine \& Nanobiotechnology

Journal of Neonatology \& Clinical Pediatrics

Journal of Nephrology \& Renal Therapy

Journal of Non Invasive Vascular Investigation

Journal of Nuclear Medicine, Radiology \& Radiation Therapy

Journal of Obesity \& Weight Loss

Journal of Orthopedic Research \& Physiotherapy

Journal of Otolaryngology, Head \& Neck Surgery

Journal of Protein Research \& Bioinformatics

Journal of Pathology Clinical \& Medical Research

Journal of Pharmacology, Pharmaceutics \& Pharmacovigilance

Journal of Physical Medicine, Rehabilitation \& Disabilities

Journal of Plant Science: Current Research

Journal of Psychiatry, Depression \& Anxiety

Journal of Pulmonary Medicine \& Respiratory Research

Journal of Practical \& Professional Nursing

Journal of Reproductive Medicine, Gynaecology \& Obstetrics

Journal of Stem Cells Research, Development \& Therapy

Journal of Surgery: Current Trends \& Innovations

Journal of Toxicology: Current Research

Journal of Translational Science and Research

Trends in Anatomy \& Physiology

Journal of Vaccines Research \& Vaccination

Journal of Virology \& Antivirals

Archives of Surgery and Surgical Education

Sports Medicine and Injury Care Journal

International Journal of Case Reports and Therapeutic Studies

Submit Your Manuscript: http://www.heraldopenaccess.us/Online-Submission.php 